\title{
CATARATA E A EXPRESSÃO CROMÁTICA NA OBRA DE MONET
}

Cristina de Jesus Sousa, Universidade Católica de Brasília, cristinadejesussousa@msn.com Maria Liz Cunha de Oliveira, Universidade Católica de Brasília, lizcunhad@gmail.com Lucy Oliveira Gomes, Universidade Católica de Brasília, lucygomes@pos.ucb.br

\section{RESUM0}

Introdução: A obra de Monet foi analisada no reflexo da deterioração de sua visão nos seus trabalhos. Analisou-se, por meio de algumas obras marcantes da biografia de Monet, a doença ocular catarata e o seu papel na história de vida deste pintor. Metodos: Revisão de literatura na modalidade revisão narrativa. A busca foi desenvolvida na Biblioteca Virtual de Saúde, na base de dados eletrônica Literatura Latino-Americana e do Caribe em Ciências da Saúde, no portal da Coordenação de Aperfeiçoamento de Pessoal de Nível Superior, no Google Acadêmico e em livros sobre a obra de Claude Monet e dos Impressionistas. Resultados: Pelas obras do artista, observa-se que, após 1908, quando se instala de maneira definitiva a catarata, há uma predominância do amarelo, marrom, cores vibrantes e também um nítido processo de turvamento da visão, com pinturas borradas. Observa-se, ainda, a mudança de cores ocorrida após a tardia intervenção cirúrgica, com clara diferença de percepção de cores pelo artista nos dois olhos, o direito operado e o esquerdo, não operado. Conclusão: Sua obra retrata os efeitos visuais da catarata não tratada no paciente idoso. A importância da relação médico/paciente, deve ser enfatizada por ter sido este um entrave no tratamento cirúrgico da catarata de Monet.

Palavras-chave: Monet; catarata; visão de cores; visão ocular 